\title{
Anthranilamide from Streptomyces spp. inhibited Xanthomonas oryzae biofilm formation without affecting cell growth
}

\author{
Youngseok Ham ${ }^{1}$ - Tae-Jong $\operatorname{Kim}^{1}$ (D)
}

Received: 22 August 2018/Accepted: 10 October 2018/Published online: 19 October 2018

(C) The Korean Society for Applied Biological Chemistry 2018

\begin{abstract}
Xanthomonas oryzae (Xoo) causes bacterial blight in rice, which reduces crop yield and leads to significant economic damage. Xoo exerts its pathogenicity by biofilm formation, interfering with sap flow in the xylem vessels. Inhibition of Xoo biofilm formation may therefore alleviate the symptoms of bacterial blight and restore rice yields. Streptomyces spp. are soil bacteria that produce various secondary metabolites. In the present study, 38,888 extracts derived from Streptomyces spp. were screened for their ability to inhibit Xoo biofilm formation; four extracts exhibited strong inhibitory activity. Separation and purification of the extracts from strains 0320 and 4359 suggested that anthranilamide was the chemical responsible for this effect. Anthranilamide was found to inhibit biofilm formation without affecting Xoo cell growth; it is, therefore, a good candidate chemical for the treatment of bacterial blight in rice as it will not give rise to resistant bacterial strains. The selected four Streptomyces strains were also good candidates for biological treatment of bacterial blight in rice.
\end{abstract}

Keywords Anthranilamide - Bacterial blight - Biofilm . Streptomyces $\cdot$ Xanthomonas oryzae

Electronic supplementary material The online version of this article (https://doi.org/10.1007/s13765-018-0405-1) contains supplementary material, which is available to authorized users.

Tae-Jong Kim

bigbell@kookmin.ac.kr

1 Department of Forest Products and Biotechnology, College of Science and Technology, Kookmin University, 77 Jeongneung-ro, Seongbuk-gu, Seoul 02707, Republic of Korea

\section{Introduction}

Xanthomonas oryzae pv. oryzae (Xoo) causes bacterial blight in rice, which reduces crop yield and leads to significant economic damage. Currently, there are no practical methods available for treating bacterial blight in paddy fields. Antibacterial chemicals can control Xoo infection $[1,2]$, but the application of antibiotic chemicals in paddy fields is impractical. Moreover, persistent use of antibiotic chemicals can lead to the development of antibiotic-resistant bacterial strains. Developing new Xoo-resistant rice varieties is a possibility, but these strains eventually become vulnerable to bacterial blight [3]. The ideal method of treating bacterial blight is through a biological approach using effective microbes $[4,5]$, which can be cultured during compost preparation and propagate in paddy fields.

One of the pathogenic mechanisms of Xoo involves biofilm formation in the xylem vessels, which interferes with sap flow [6, 7]. Upon Xoo infection, the xylem vessels in susceptible rice strains are blocked by Xoo biofilms, while those in resistant strains are not [6]. Interestingly, Xoo can be observed in tissues around the xylem vessels of resistant rice strains, indicating that although the symptoms of bacterial blight are only observed in susceptible strains, Xoo can infect both types of rice.

The xylem vessels are crucial for nutrient and water transport in plants. Consequently, rice yield is significantly reduced by the formation of Xoo biofilm in the xylem vessels during bacterial blight infection. Hence, the prevention of Xoo biofilm formation may alleviate bacterial blight symptoms and restore crop yields in susceptible rice strains to the levels observed in resistant rice strains. In addition, biofilm formation protects Xoo cells in natural 
environments and increases the occurrence of rice bacterial blight.

Streptomyces spp. are soil bacteria that produce a variety of secondary metabolites, including antibiotics, antifungal agents, and immune suppressors. They can be used to improve the resistance of crops to infectious diseases [8-12]; several studies have shown that actinomycetes inhibit the biofilm formation of various pathogenic bacteria [13-16]. It is therefore possible that Xoo biofilm-inhibiting chemicals may be produced by Streptomyces spp. Streptomyces bottropensis has been shown to effectively eliminate bacterial blight through its antibiotic activities, although it does not inhibit Xoo biofilm formation [17]. Using nonpathogenic, soil-derived Streptomyces spp. to treat bacterial blight will minimize damage to the environment because no infectious or harmful agents are involved. It will be beneficial, therefore, to screen Streptomyces spp. for biological agents to treat bacterial blight.

A chemical extract library of Streptomyces spp. is available from the Extract Collection of Useful Microorganisms (ECUM) at Myongji University, Yongin, Korea. The ECUM actively collects soils from diverse climates and isolates actinomycetes, mainly Streptomyces spp., from these soils. More than 100,000 extracts are currently available. In the present study, we screened approximately 40,000 extracts from more than 5000 Streptomyces spp. isolated from soils to evaluate the potential use of Streptomyces spp. as a biological treatment for bacterial blight by inhibiting Xoo biofilm formation.

\section{Materials and methods}

\section{Xoo strains and culture conditions}

Xoo strain KACC 10,331 was purchased from the Rural Development Administration Genebank of Jeonju, Korea. Yeast extract-glucose-calcium carbonate (YGC) agar plates on which Xoo were grown contained $50 \mathrm{~g} / \mathrm{L}$ glucose, $5 \mathrm{~g} / \mathrm{L}$ yeast extract, $12.5 \mathrm{~g} / \mathrm{L}$ calcium carbonate, and $15 \mathrm{~g} /$ L agar. Medium 210 [18], a liquid Xoo growth medium, and XOM2 medium [19], used for the Xoo biofilm formation assay, were prepared according to previous methods. Anthranilamide was purchased from Thermo Fisher Scientific Korea Ltd. (Seoul, Korea).

\section{Streptomyces spp. extract library from the ECUM}

A Streptomyces spp. extract library was provided by the ECUM at Myongji University, Yongin, Korea (http://www. ecum.or.kr/). Details of the library construction are accessible on the Web site, but some essential information follows. Single actinomycetes colonies were separated from soils. The extract library was prepared by independently culturing cells in four different media, including glucosestarch-soybean medium (GSS medium), modified Bennett's medium (MBN medium), dextrin-soybean-corn starch liquor medium (DSC medium), and dextrin-yeastcorn starch liquor medium (DYC medium). The GSS medium used to grow Streptomyces cells of ECUM strain registration numbers $1-5085$ contained $20 \mathrm{~g} / \mathrm{L}$ glucose, $10 \mathrm{~g} / \mathrm{L}$ soluble starch, $25 \mathrm{~g} / \mathrm{L}$ soybean meal, $1 \mathrm{~g} / \mathrm{L}$ beef extract, $4 \mathrm{~g} / \mathrm{L}$ yeast extract, $2 \mathrm{~g} / \mathrm{L} \mathrm{NaCl}, 0.25 \mathrm{~g} / \mathrm{L} \mathrm{K}_{2} \mathrm{HPO}_{4}$, and $2 \mathrm{~g} / \mathrm{L} \mathrm{CaCO}_{3}$ at $\mathrm{pH}$ 7.2. MBN medium, which was used to grow Streptomyces cells of ECUM strain registration numbers 240-5085, was prepared according to a previous method [20], with "N-Z-amine A" replaced by Bacto Peptone. DSC medium, used to grow Streptomyces cells of ECUM strain registration numbers 1277-3075, was a liquid medium containing high molecular weight nutrients: $30 \mathrm{~g} / \mathrm{L}$ dextrin, $15 \mathrm{~g} / \mathrm{L}$ soybean flour, $15 \mathrm{~g} / \mathrm{L}$ corn starch liquor, $5 \mathrm{~g} / \mathrm{L} \mathrm{CaCO}_{3}, 2 \mathrm{~g} / \mathrm{L}$ polypeptone, $1 \mathrm{~g} / \mathrm{L} \mathrm{Na}_{2} \mathrm{~S}_{2} \mathrm{O}_{3}$, and $1.8 \mathrm{~g} / \mathrm{L} \mathrm{CoCl}_{2}$. DYC medium, for growing Streptomyces cells of ECUM strain registration numbers 3076-5085, was also a liquid medium containing high molecular weight nutrients: $25 \mathrm{~g} / \mathrm{L}$ dextrin, $12 \mathrm{~g} / \mathrm{L}$ dry yeast, $20 \mathrm{~g} / \mathrm{L}$ corn starch liquor, $1 \mathrm{~g} / \mathrm{L} \mathrm{NaBr}$, and $1 \mathrm{~g} / \mathrm{L}$ $\mathrm{CoCl}_{2}$ at $\mathrm{pH} 7.0$. After growth at $26^{\circ} \mathrm{C}$ for $120 \mathrm{~h}$ in the respective media and harvesting of cells by centrifugation, chemical compounds in Streptomyces spp. cells were extracted using methanol, and compounds in the culture supernatant were separated using ethyl acetate and water. In the present study, a partial extract library of ECUM strains, which comprised 38,888 cell-free extracts from 5085 actinomycete strains, was used.

\section{Quantitative biofilm assay}

Xoo stored in a frozen stock at $-80^{\circ} \mathrm{C}$ was inoculated into $5 \mathrm{~mL}$ medium 210 and grown on YGC agar plates at $28^{\circ} \mathrm{C}$ for $48 \mathrm{~h}$ with shaking at $250 \mathrm{rpm}$. For biofilm assays, Xoo was subcultured in $100 \mu \mathrm{L}$ XOM2 medium in 96-well polyvinyl chloride (PVC) microplates to an optical density at $600 \mathrm{~nm}\left(\mathrm{Abs}_{600}\right)$ of 0.05 . Inoculated culture media in 96-well microplates were incubated for $24 \mathrm{~h}$ at $28^{\circ} \mathrm{C}$. Quantitative biofilm analysis was performed by crystal violet assay according to a previous method [21]. The absorbance value at $595 \mathrm{~nm}\left(\mathrm{Abs}_{595}\right)$ represented the amount of biofilm. Cells that had not been inoculated were used as blank controls. The absorbance values of the samples were subtracted from the value of the blank controls to calculate the relative absorbance of the samples. The effect of Streptomyces spp. extracts on Xoo biofilm formation was evaluated by comparison of the absorbance value at $595 \mathrm{~nm}$ of the sample biofilm formation and the control biofilm formation, tested on the same 96-well 
microplate with $5 \mu \mathrm{L}$ dimethyl sulfoxide, which was the solvent used to dissolve the extracts.

\section{High-throughput screening for inhibitors of biofilm formation}

Streptomyces spp. extracts from the ECUM were provided in lyophilized form in 96-well microplates. XOM2 medium $(100 \mu \mathrm{L})$ was added to each well. Extracts $(5 \mu \mathrm{L})$ were used for the inhibitory activity assay of Xoo biofilm formation in a 96-well PVC microplate. The inhibitory activity of the samples was calculated by comparison with the control, i.e., Xoo biofilm formation with $5 \mu \mathrm{L}$ dimethyl sulfoxide.

\section{Purification of active chemicals}

The methanol extracts of strains 0320 (E0320) and 4359 (E4359) were purchased from the ECUM. Their weights were $12.44 \mathrm{~g}$ and $25.05 \mathrm{~g}$, respectively. The purification steps are illustrated in Supplementary Figs. 1 and 2, respectively. The purchased extracts were separated by liquid-liquid extraction from $200 \mathrm{~mL}$ water, using $200 \mathrm{~mL}$ ethyl acetate three times for E0320 and four times for E4359. The remaining water partition was further separated by liquid-liquid extraction using $200 \mathrm{~mL}$ butanol three times for both extracts. The butanol partition was concentrated using a Rotavapor ${ }^{\circledR}$ R-124 (Büchi Labortechnik AG, Flawil, Switzerland) and freeze-dried (FDUT-12006, Operon Co., Ltd., Kimpo, Korea) giving samples hereinafter referred to as $\mathrm{E} 0320_{\mathrm{B}}$ and $\mathrm{E} 4359_{\mathrm{B}}$. After dissolving powdered $\mathrm{E}^{2} 320_{\mathrm{B}}(3.60 \mathrm{~g})$ and $\mathrm{E} 4359_{\mathrm{B}}(6.05 \mathrm{~g})$ in methanol, the chemicals in the extracts were separated by vacuum column chromatography (VCC) using a column packed with silica gel 60G (catalog number: 107731, 400 mesh size, Merck Millipore Korea, Seoul, Korea). The bound chemicals of $\mathrm{E} 0320_{\mathrm{B}}$ were eluted with a mixture of dichloromethane and methanol in a ratio of $10: 1$ or 1:1 and named $\mathrm{E} 0320_{\mathrm{B} 10}$ and $\mathrm{E} 0320_{\mathrm{B} 1}$, respectively. The bound chemicals of $\mathrm{E} 4359_{\mathrm{B}}$ were eluted with a 3:1 mixture of dichloromethane and methanol and named $\mathrm{E} 4359_{\mathrm{B} 1-}$ $\mathrm{E} 4359_{\mathrm{B} 8}$. The remaining bound chemicals of $\mathrm{E} 4359_{\mathrm{B}}$ were finally eluted with methanol and named E4359 $\mathrm{BM}$. The $\mathrm{E} 0320_{\mathrm{B} 1}$ and $\mathrm{E} 4359_{\mathrm{BM}}$ fractions were concentrated using a Rotavapor ${ }^{\circledR}$ R-124 (Büchi Labortechnik AG) and freezedried (FDUT-12006, Operon Co., Ltd.). After dissolving powdered $\mathrm{E} 0320_{\mathrm{B} 1}(1.30 \mathrm{~g})$ and $\mathrm{E} 4359_{\mathrm{BM}}(1.86 \mathrm{~g})$ in methanol, the chemicals in the extracts were separated by VCC using a column packed with silica gel 60G (Merck Millipore Korea). The bound chemicals of $\mathrm{E} 0320_{\mathrm{B} 1}$ and E4359 ${ }_{\mathrm{BM}}$ were eluted with a 2:1 mixture of dichloromethane and methanol and named E0320 $0_{\mathrm{B} 1-1}-\mathrm{E} 0320_{\mathrm{B} 1-3}$ and $\mathrm{E} 4359_{\mathrm{BM} 1}-\mathrm{E} 4359_{\mathrm{BM} 2}$, respectively. The remaining bound chemicals of $\mathrm{E} 0320_{\mathrm{B} 1}$ and $\mathrm{E} 4359_{\mathrm{BM}}$ were finally eluted with methanol and named $\mathrm{E} 0320_{\mathrm{B} 1-\mathrm{M}}$ and E4359 $9_{\mathrm{BMM}}$, respectively. The methanol-eluted fractions, E0320 $\mathrm{B1-M}$ and $\mathrm{E} 4359_{\mathrm{BMM}}$, were concentrated using a Rotavapor $^{\circledR}$ R-124 (Büchi Labortechnik AG) and freezedried (FDUT-12006, Operon Co., Ltd.). After dissolving powdered $\mathrm{E} 0320_{\mathrm{B} 1-\mathrm{M}}(93 \mathrm{mg})$ and $\mathrm{E} 4359_{\mathrm{BMM}}(808 \mathrm{mg})$ in methanol, the chemicals in the extracts were separated by reversed-phase chromatography using a column packed with LiChroprep ${ }^{\circledR}$ RP-18 (size: $25-40 \mu \mathrm{m}$, Merck Millipore Korea). The bound chemicals of E0320 1 1-M and E4359 $9_{\text {BMM }}$ were eluted with a mixture of methanol and water in a ratio of $3: 2$ and $2: 1$, respectively, and named $\mathrm{E} 0320_{\mathrm{B} 1-\mathrm{M} 1}-\mathrm{E} 0320_{\mathrm{B} 1-\mathrm{M} 6}$ and $\mathrm{E} 4359_{\mathrm{BMM}-1}-\mathrm{E} 4359_{\mathrm{BMM}-7}$, respectively. The remaining bound chemicals of $\mathrm{E} 0320_{\mathrm{B} 1-\mathrm{M}}$ and $\mathrm{E} 4359_{\mathrm{BMM}}$ were finally eluted with methanol and named E0320 $0_{\mathrm{B} 1-\mathrm{MM}}$ and $\mathrm{E} 4359_{\mathrm{BMM}-\mathrm{M}}$, respectively. The inhibitory effect of each fraction on biofilm formation was evaluated.

\section{Separation and analysis of chemicals by high- performance liquid chromatography (HPLC)-mass spectrometry (MS)}

This analysis was performed at the National Instrumentation Centre for Environmental Management (Seoul, Korea). Powdered E0320 ${ }_{\mathrm{B} 1-\mathrm{M} 4}$ and E4359 ${ }_{\mathrm{BMM}-6}$ were dissolved in water at 1.0 and $22.5 \mathrm{mg} / \mathrm{mL}$, respectively. Then, they were analyzed by HPLC (Dionex UltiMate ${ }^{\mathrm{TM}} 3000$ standard systems, Thermo Scientific Korea Ltd., Seoul, Korea) using a mass spectrometer (LTQ Orbitrap, Thermo Scientific Korea Ltd.) as a detector. The column was Unison UK-C18 (column length $100 \mathrm{~mm}$; internal column diameter $2 \mathrm{~mm}$; resin diameter $3 \mu \mathrm{m}$; product number UK024; Imtakt Co., Kyoto, Japan). The mobile phase solution A was water with $0.1 \%$ formic acid, and the mobile phase solution B was acetonitrile with $0.1 \%$ formic acid. Chromatographic separation was performed using a 9:1 mixture of solutions $\mathrm{A}$ and $\mathrm{B}$ as the mobile phase at a flow rate of $0.2 \mathrm{~mL} / \mathrm{min}$. The injected sample volume was $10 \mu \mathrm{L}$.

\section{Results}

\section{Four Streptomyces spp. extracts with the strongest inhibitory activity against $\mathrm{Xoo}$ biofilm formation}

In the initial screening stage, a total of 38,888 extracts from 5085 individual Streptomyces spp. in the ECUM library were tested for their inhibitory activity against Xoo biofilm formation in 96-well microplates. The number of valid results was 35,712 , excluding unreliable samples that 
showed inconsistent biofilm formation. Based on the results of the first screening stage, 1383 extracts were selected and inhibitory activity against Xoo biofilm formation was re-evaluated in the second stage of screening. From the secondary screening, 63 extracts were chosen. These 63 selected extracts were purchased from the ECUM to re-evaluate their inhibitory activity on Xoo biofilm formation using fresh extracts. In the third stage of screening, the inhibitory activity of the extracts in dilutions of up to 30-fold was tested. Only five extracts retained strong inhibitory activity at $47 \mathrm{mg} / \mathrm{L}$. Two out of the final five extracts were from the same strain and culture medium (ECUM strain registration number 1144 and GSS medium), but from different extract solutions (methanol for cells and water for culture media), and the water extract was selected for further studies. The final four selected extracts are listed in Table 1 . The $16 \mathrm{~S}$ ribosomal RNA genes of these four strains were sequenced. Taxonomic identification confirmed that all four strains belonged to the genus Streptomyces. GSS culture medium was used for all four selected extracts. Two samples were extracted with methanol from the cell pellets, while two were extracted with water from the culture media. The abilities of the four selected extracts to inhibit Xoo biofilm formation are shown in Fig. 1. All extracts showed a strong inhibitory activity at concentrations above $50 \mathrm{mg} / \mathrm{L}$ (Fig. 1) without inhibiting Xoo cell growth (Supplementary Fig. 3).

\section{Purification and isolation of inhibitory chemicals}

The methanol extract components of strains 0320 and 4359, which included both hydrophobic and hydrophilic chemicals, were separated to identify the compounds responsible for the inhibitory effect. The separation process for the strain 0320 methanol extract (E0320) is illustrated in Supplementary Fig. 1 and for the strain 4359 methanol extract (E4359) in Supplementary Fig. 2. During the separation process, the inhibitory activity of each fraction was evaluated (Fig. 2). In the first step, the extracts were partitioned according to their solubility in water, ethyl acetate, or butanol. The butanol fractions of both E0320 and E4359 showed strong and specific inhibitory activity (Fig. 2A, B, respectively). In following two separation steps for E0320 $\mathrm{B}$, the specific inhibitory activity of the isolated fraction increased dramatically (Fig. 2C, E). However, after one further separation step with E0320 1 1-M, all fractions displayed decreased specific inhibitory activity. In the case of the E4359 extract, the second separation (Fig. 2D) increased the specific inhibitory activity as much as the third separation of E0320 (Fig. 2E). The next two separation steps with $\mathrm{E} 4359_{\mathrm{BM}}$ decreased the specific activity (Fig. 2F, H).

After separation, the final fractions $\left(\right.$ E0320 ${ }_{\mathrm{B} 1-\mathrm{M} 4}$ and

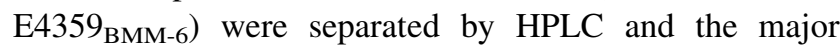
peaks were analyzed by MS (Supplementary Figs. 4 and 5, respectively). The detected masses are listed in Table 2. Interestingly, there were two chemicals with the same mass, 158.96 and $226.95 \mathrm{Da}$, in the E0320 ${ }_{\mathrm{B} 1-\mathrm{M} 4}$ and E4359 ${ }_{\text {BMM-6 }}$ fractions. Considering the differences between the 0320 and 4359 strains observed from their $16 \mathrm{~S}$ rRNA sequences, the existence of two identical chemicals was unexpected. We identified the likely inhibitory compound based on this information.

\section{Anthranilamide inhibited $X o o$ biofilm formation}

Since the chemical inhibiting Xoo biofilm formation is a product of Streptomyces spp., we searched for chemicals produced from Streptomyces spp. with the determined molecular weight rather than conducting further analysis for chemical identification. Anthranilamide is produced by a marine Streptomyces sp. [22]. Its molecular weight is 136.15 Da. If a sodium ion $(22.99 \mathrm{Da})$ is added, anthranilamide might have a molecular weight of 159.14 Da during mass spectrophotometry. In order to confirm the existence of anthranilamide in the selected extracts, we analyzed the extracts using HPLC (Supplementary Fig. 6). A peak with a similar retention time to that of anthranilamide strongly suggested the presence of anthranilamide in E4359 and E4359 ${ }_{\text {BMM-6. }}$

Finally, the inhibitory activity of anthranilamide on Xoo biofilm formation was measured (Fig. 3). Anthranilamide inhibited biofilm formation by $88 \%$ without inhibiting Xoo cell growth at concentrations from 30 to $120 \mathrm{mg} / \mathrm{L}$.

Table 1 Four cell-free extracts obtained from the extract library of Streptomyces spp. and grown in GSS medium, with the strongest inhibition activity on biofilm formation of Xanthomonas oryzae after three stages of screening

\begin{tabular}{llll}
\hline ECUM strain registration number & Strain name & GenBank accession number & Solution used for extraction \\
\hline 0320 & Streptomyces sp. MJM320 & JQ218925 & Methanol \\
1144 & Streptomyces sp. MJM1144 & JQ218926 & Water \\
1352 & Streptomyces sp. & Unregistered & Water \\
4359 & Streptomyces prasinus & JQ218927 & Methanol \\
\hline
\end{tabular}


Fig. 1 Ability of the four extracts to inhibit Xoo biofilm formation selected after three stages of screening. The extract concentrations on the $x$-axis are the calculated final concentrations in the biofilm formation solution. Biofilm was quantified by crystal violet assay. Inhibitory activities are shown for (A) E0320 (strain 0320 methanol extract), (B) E1144 (strain 1144 water extract), (C) E1352 (strain 1352 water extract), and (D) E4359 (strain 4359 methanol extract)


(C)

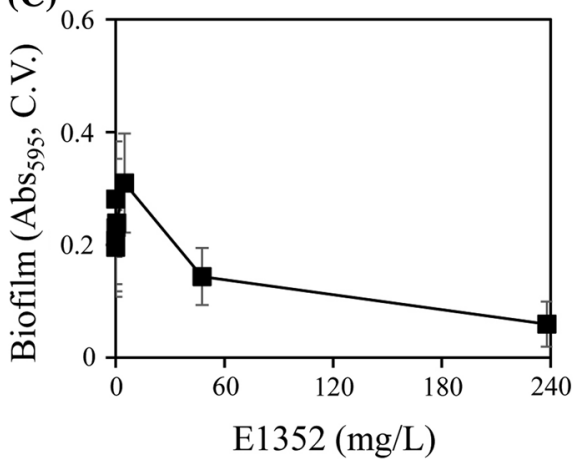

\section{Discussion}

In the present study, the ability of Streptomyces spp. extracts to inhibit Xoo biofilm formation was evaluated using a high-throughput screening method. Almost $75 \%$ of the tested extracts inhibited biofilm formation. This abundance of inhibitory activity in the extract library suggested that many Streptomyces spp. produce chemicals capable of inhibiting Xoo biofilm formation, which is in agreement with a previous study [17].

After three stages of high-throughput screening, the four strongest inhibitory extracts were selected. All four extracts originated from the genus Streptomyces, according to their 16S rRNA sequences and the morphology of the cells and colonies. Moreover, all four selected extracts were derived from Streptomyces grown in GSS medium. Water was used for making two of the extracts and methanol for the other two extracts listed in Table 1 . The inhibitory chemicals of the two water extracts were hydrophilic. However, the hydrophobicity of the inhibitory chemicals in the two methanol extracts was unclear. Based on the fact that that methanol extracted inhibitory chemicals from cells regardless of their hydrophobicity and that the water and ethyl acetate extracts (used for solvent fractionation of culture solution by hydrophobicity) of the same strain had no inhibitory activity (data not shown), the inhibitory chemicals of Streptomyces sp. 0320 and Streptomyces sp. 4359 remained inside the cells.
In an effort to identify the inhibitory chemicals, the extracts of E0320 and E4359 were separated and analyzed. Anthranilamide has been suggested as a chemical that matches the analyzed molecular weight of the inhibitory compound produced by Streptomyces sp. Anthranilamide did not affect the growth of Xoo and selectively inhibited the biofilm formation. This observation implies that anthranilamide is one of the active chemicals in the two selected extracts (E0320 and E4359) with the same effects shown in Fig. 1 and Supplementary Fig. 3.

The formation of biofilms in natural environments such as rice paddies provides $\mathrm{Xoo}$ with resistance to various environmental stresses and the opportunity to infect rice without being washed away. After infection, it was observed that Xoo formed a biofilm in the transport tissue of rice to interfere with the flow of fluids and more so in the xylem than the phloem. This interference was suggested to be the main cause of the symptoms of bacterial blight $[6,7]$. If Xoo biofilm formation is suppressed, not only can Xoo be eliminated from the environment, but even after Xoo infection the symptoms of bacterial blight are suppressed and normal rice crop yield can be expected. The present study provides a method for inhibiting Xoo biofilm formation.

In 1998, MA Farooq Biabani et al. [22] isolated and identified anthranilamide from Streptomyces strain B7747 from Laguna de Términos sediments located in the Gulf of Mexico. Anthranilamide had an antimicroalgal effect on four algae, including Chlorella vulgaris, $C$. sorokiniana, $C$. 
Fig. 2 Biofilm inhibitory activity of fractions in the purification procedure using E0320 and E4359. The concentration on the $x$-axis is the calculated final concentration in the biofilm formation solution. Biofilm was quantified by crystal violet assay. Inhibitory activities are shown for (A) E0320 $0_{\mathrm{B}}$,

(B) $\mathrm{E} 4359_{\mathrm{B}}$, (C) $\mathrm{E} 0320_{\mathrm{B} 1}$,

(D) $\mathrm{E} 4359_{\mathrm{BM}}$, (E) $\mathrm{E} 0320_{\mathrm{B} 1-\mathrm{M}}$,

(F) $\mathrm{E}^{4} 359_{\mathrm{BMM}}$, (G) E0320 $\mathrm{B} 1-\mathrm{M} 4$, and (H) E4359 ${ }_{\text {BMM- }}$
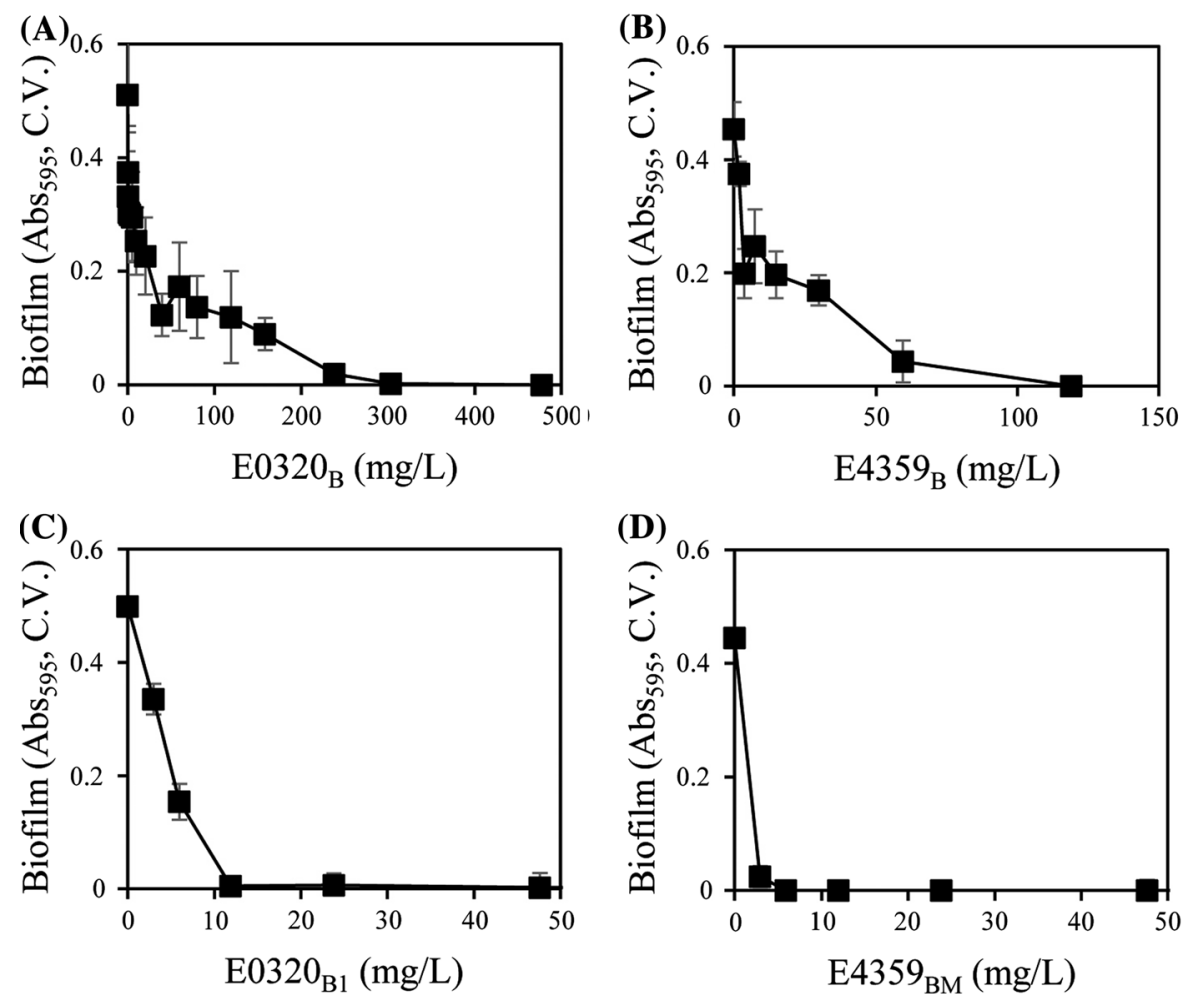

(E)

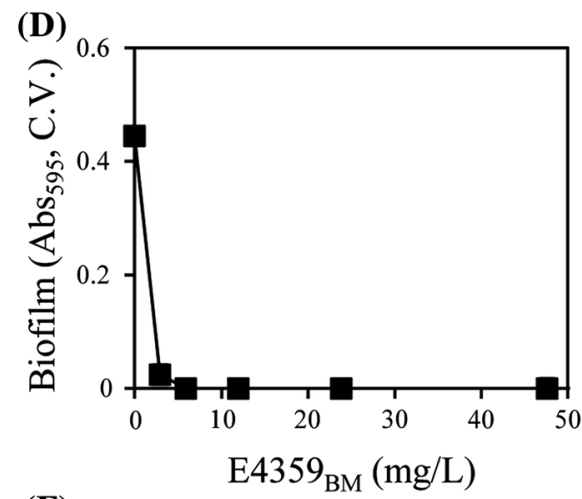

(F)
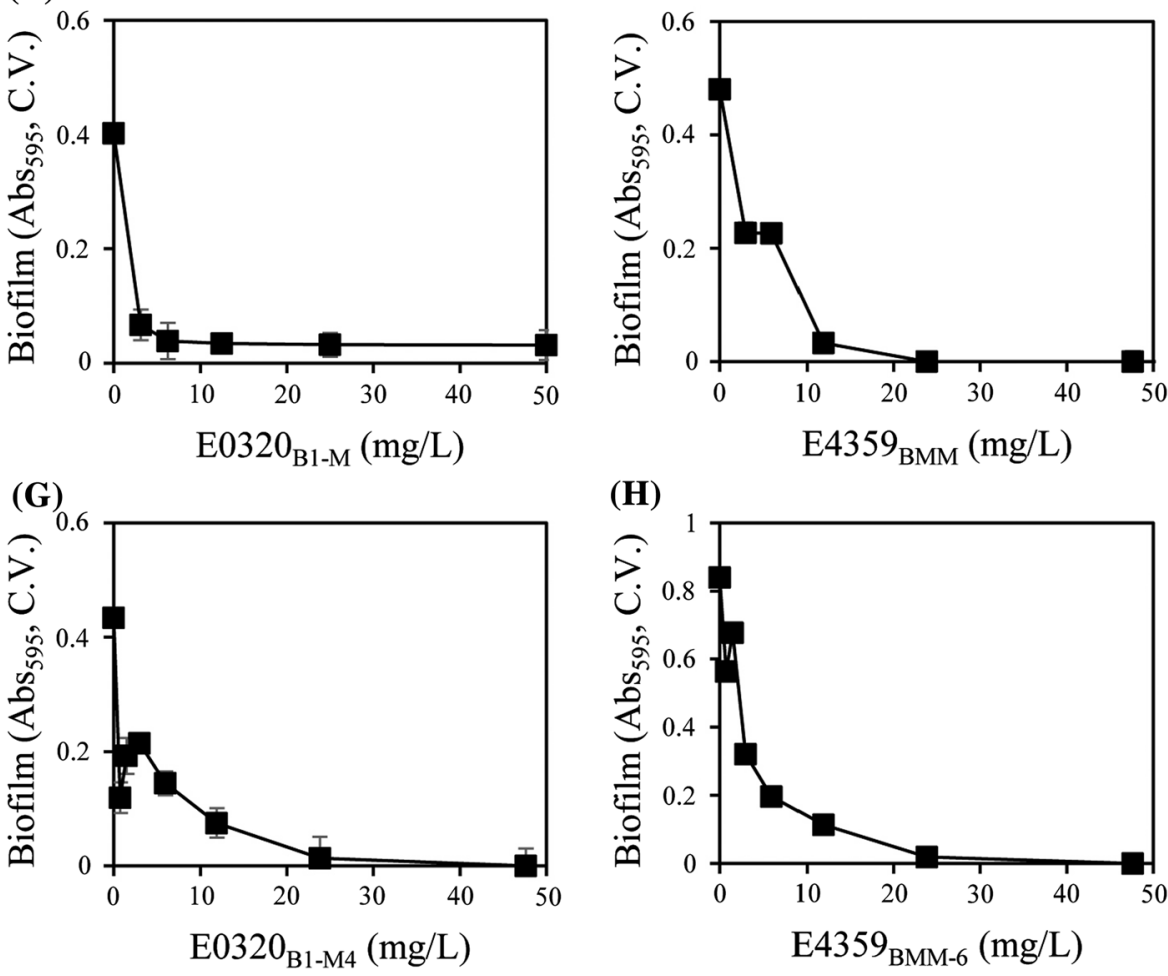

(H)

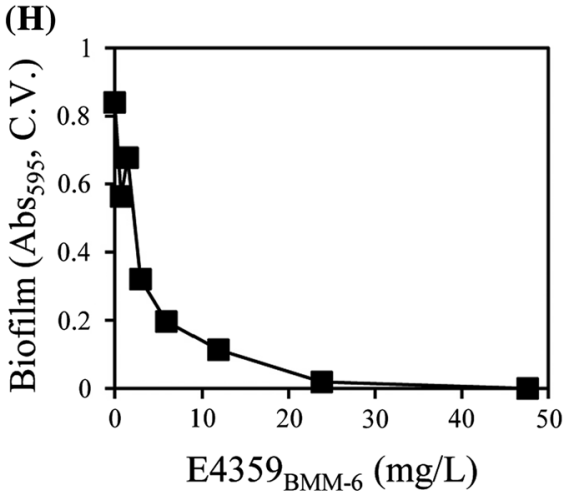

salina, and Scenedesmus subspicatus. However, to the best of our knowledge, there are no studies to date on the inhibition of Xoo biofilm formation by anthranilamide.

Anthranilamide produced from Streptomyces spp. did not affect the growth of Xoo and selectively inhibited biofilm formation. In general, as bacteria grow, many organic materials are produced and biofilm formation is promoted. Resistant bacteria will appear when Xoo is killed by long-term application of chemicals, such as antibiotics, intended to inhibit biofilm formation. To overcome this 
Table 2 Molecular weights of chemicals corresponding to the peaks of $\mathrm{E} 0320_{\mathrm{B} 1-\mathrm{M} 4}$ and $\mathrm{E} 4359_{\mathrm{BMM}-6}$ in high-performance liquid chromatography and mass spectrometry

\begin{tabular}{ll}
\hline Retention time $(\mathrm{min})$ & Molecular weight $(\mathrm{Da})$ \\
\hline E0320 ${ }_{\mathrm{B} 1-\mathrm{M} 4}$ & \\
$0.98-1.05$ & $90.98,158.96,226.95,282.09$ \\
$1.35-1.42$ & $89.06,148.06,282.09$ \\
$2.76-2.80$ & $168.06,335.11$ \\
E4359 & \\
$0.97-1.01$ & $158.96,226.95$ \\
$1.12-1.19$ & 118.08 \\
1.59 & 132.10 \\
$1.76-1.83$ & 585.31 \\
$2.03-2.06$ & 614.27 \\
$2.98-3.05$ & $158.00,261.14$ \\
\hline
\end{tabular}
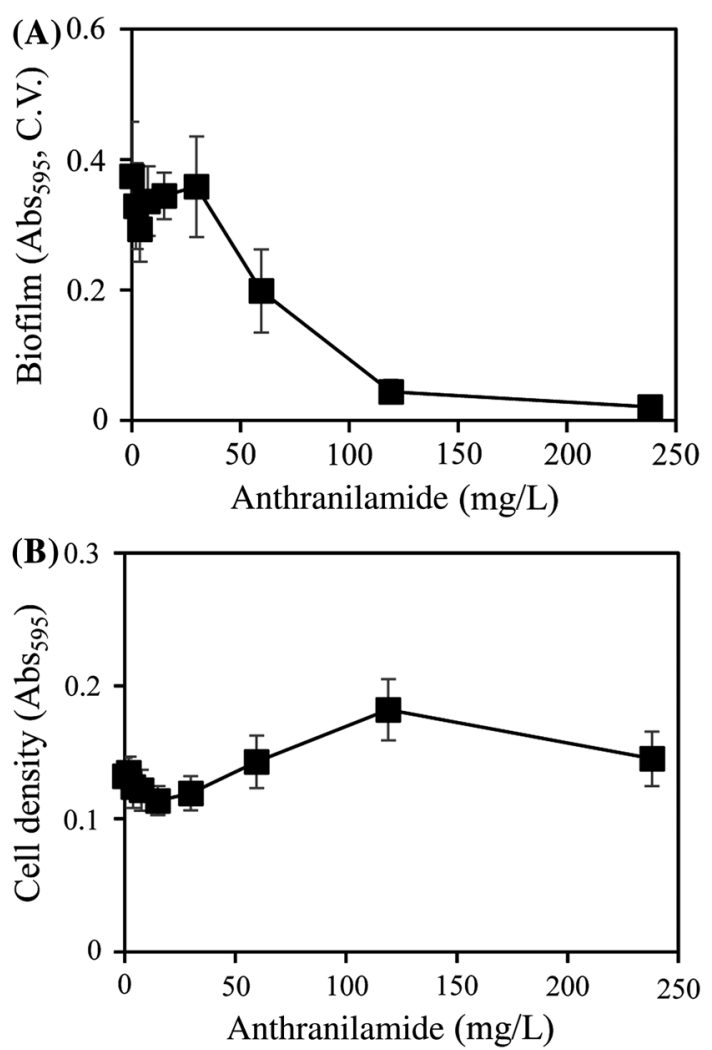

Fig. 3 Effect of anthranilamide on biofilm formation and Xoo cell growth. Biofilm was quantified by crystal violet assay (A), and cell growth was measured using a spectrophotometer $(\mathbf{B})$

problem, it is necessary to treat infectious diseases or alleviate symptoms by other methods. The selective inhibition of biofilm formation by anthranilamide achieves this, as it can alleviate the symptoms of bacterial blight independently of Xoo growth. Anthranilamide can provide a unique method for developing an agricultural chemical to treat bacterial blight that can be continuously applied without the appearance of resistant bacteria. In addition, by observing the physiological changes in Xoo treated with anthranilamide, the biological mechanism of Xoo biofilm formation will be revealed and additional methods to selectively inhibit it may be proposed.

Applying anthranilamide directly in rice paddies may cause a variety of environmental problems, since the effect of anthranilamide on ecosystem has not been studied yet. Anthranilamide is produced from Streptomyces spp. isolated from soil. By controlling the cultivation environment of rice in favor of natural producing anthranilamide from Streptomyces spp., the symptoms of bacterial blight can be alleviated and rice yield can be restored. However, further studies are required to demonstrate that rice absorbs anthranilamide from the soil. Using soil microorganisms rather than chemicals is an environmentally friendly biological method of treating bacterial blight. For this purpose, using the four selected Streptomyces strains as a biological treatment method for bacterial blight in rice may also be possible.

Acknowledgments This research was supported by "Cooperative Research Program for Agriculture Science and Technology Development (Project No. PJ013896032018)" Rural Development Administration, Republic of Korea.

\section{References}

1. Gnanamanickam SS, Priyadarisini VB, Narayanan NN, Vasudevan P, Kavitha S (1999) An overview of bacterial blight disease of rice and strategies for its management. Curr Sci India 77:1435-1443

2. Singh RA, Das B, Ahmed KM, Pal V (1980) Chemical control of bacterial leaf blight of rice. Trop Pest Manag 26:21-25

3. Mew TW, Vera Cruz CM, Medalla ES (1992) Changes in race frequency of Xanthomonas oryzae pv. oryzae in response to rice cultivars planted in the Philippines. Plant Dis 76:1029-1032

4. Ji G-H, Wei L-F, He Y-Q, Wu Y-P, Bai X-H (2008) Biological control of rice bacterial blight by Lysobacter antibioticus strain 13-1. Biol Control 45:288-296

5. Velusamy P, Immanuel JE, Gnanamanickam SS, Thomashow L (2006) Biological control of rice bacterial blight by plant-associated bacteria producing 2,4-diacetylphloroglucinol. Can J Microbiol 52:56-65

6. Han S-W, Park C-J, Lee S-W, Ronald P (2008) An efficient method for visualization and growth of fluorescent Xanthomonas oryzae pv. oryzae in planta. BMC Microbiol 8:164

7. Mew TM, Alvarez AM, Leach JE, Swings J (1993) Focus on bacterial blight of rice. Plant Dis 77:5-12

8. Poovarasan S, Mohandas S, Paneerselvam P, Saritha B, Ajay KM (2013) Mycorrhizae colonizing actinomycetes promote plant growth and control bacterial blight disease of pomegranate $(\mathrm{Pu}$ nica granatum L. cv Bhagwa). Crop Prot 53:175-181 
9. Palaniyandi S, Yang S, Zhang L, Suh J-W (2013) Effects of actinobacteria on plant disease suppression and growth promotion. Appl Microbiol Biotechnol 97:9621-9636

10. Wiggins BE, Kinkel LL (2005) Green manures and crop sequences influence potato diseases and pathogen inhibitory activity of indigenous streptomycetes. Phytopathology 95:178-185

11. Inbar E, Green S, Hadar Y, Minz D (2005) Competing factors of compost concentration and proximity to root affect the distribution of streptomycetes. Microb Ecol 50:73-81

12. Cao L, Qiu Z, You J, Tan H, Zhou S (2005) Isolation and characterization of endophytic streptomycete antagonists of fusarium wilt pathogen from surface-sterilized banana roots. FEMS Microbiol Lett 247:147-152

13. Nithyanand P, Thenmozhi R, Rathna J, Pandian S (2010) Inhibition of Streptococcus pyogenes biofilm formation by coral-associated actinomycetes. Curr Microbiol 60:454-460

14. You J, Xue X, Cao L, Lu X, Wang J, Zhang L, Zhou S (2007) Inhibition of Vibrio biofilm formation by a marine actinomycete strain A66. Appl Microbiol Biotechnol 76:1137-1144

15. Kim Y-G, Lee J-H, Kim C-J, Lee J-C, Ju Y, Cho M, Lee J (2012) Antibiofilm activity of Streptomyces sp. BFI 230 and Kribbella sp. BFI 1562 against Pseudomonas aeruginosa. Appl Microbiol Biotechnol 96:1607-1617
16. Augustine N, Peter AW, Kerkar S, Thomas S (2012) Arctic actinomycetes as potential inhibitors of Vibrio cholerae biofilm. Curr Microbiol 64:338-342

17. Park SB, Lee IA, Suh J-W, Kim J-G, Lee CH (2011) Screening and identification of antimicrobial compounds from Streptomyces bottropensis suppressing rice bacterial blight. J Microbiol Biotechnol 21:1236-1242

18. Shaw JJ, Dane F, Geiger D, Kloepper JW (1992) Use of bioluminescence for detection of genetically engineered microorganisms released into the environment. Appl Environ Microbiol 58:267-273

19. Tsuge S, Furutani A, Fukunaka R, Oku T, Tsuno K, Ochiai H, Inoue Y, Kaku H, Kubo Y (2002) Expression of Xanthomonas oryzae pv. oryzae hrp genes in XOM2, a novel synthetic medium. J Gen Plant Pathol 68:363-371

20. Jones KL (1949) Fresh isolation of actinomycetes in which the presence of sporogenous aerial mycelia is a fluctuating charateristic. J Bacteriol 57:141-145

21. Kim T-J, Young BM, Young GM (2008) Effect of flagellar mutations on Yersinia enterocolitica biofilm formation. Appl Environ Microbiol 74:5466-5474

22. Biabani MAF, Baake M, Lovisetto B, Laatsch H, Helmke E, Weyland H (1998) Anthranilamides: new antimicroalgal active substances from a marine Streptomyces sp. J Antibiot 51:333-340 